\title{
Concrete Visibility - Confrontation and Relocation in Modern Images
}

Michael Kjær,

University of Copenhagen, Denmark

\begin{abstract}
The article's main hypothesis is, following Vilém

Flusser, that modern imagery in general is "technical," which means its images are images of technical concepts. As such they are difficult to distinguish phenomenologically and semiotically from their environment and therefore difficult to identify as images. The main argument is that certain modern images are capable of revealing this technicality by confronting the viewer with a concrete visibility forcing discursive relocations of the knowledge integral to perceiving them. The article develops this argument from Gottfried Boehm and Michel Foucault's understanding of images, and in connection with analyses of photographs of the Russian artist Alexander Rodchenko and paintings by the Danish painters J. F. Willumsen and Erik Hoppe.
\end{abstract}

Keywords: modernity, phenomenology, semiotics, image theory

This article will aim to answer a fundamental question which can be formulated like this: To what extent and in what forms are modern images able to perform discursive relocations of the knowledge integral to perceiving? To answer this question I will explicate two image theories. First Gottfried Boehm's theory of iconic difference and second Michel Foucault's conception of modern images as being concrete image-objects. Both Boehm and Foucault conceive of the image as founded in the factuality of matter and as such their understandings of the image have much in common. Still, the differences between them reveal important insights into modern imagery.

The influential art critic Clement Greenberg situated the critical potential of so-called "modernist" painting in the self-reflecting flatness of its medium, its implosion, or doing away with illusionist representation. Part of the argument of this article is that if Greenberg's definition is not going to turn into a banal observation stowing away modern or even modernist art into the closed-off area of its medium as self-reflection, one has in a way to allow this flatness to implode once more. This implosion consists in a concrete reappearance of the represented space in the factual medium of representation, turning this new combination into concrete "image-objects" as described by Foucault in his lecture on Manet and the Object of Painting (2009/1971). This article will try to develop how these concrete image-objects are constituted in modern images. The implicit aim is to reformulate modern art's potential from a Greenbergian knowledge-reflection to an open actual confrontation with concrete visible objects. A confrontation that triggers exactly the archaeological knowledge-relocations, we are aiming to describe in this article.

\section{LAYERINGS}

Clement Greenberg wanted to separate modern pictures from literary influence, from their subject matter, by dividing the sensual field between the arts in a "newer Laocoön" (Greenberg, 1986/1940). Vilém Flusser, to whom I will return, instead wanted us to work critically with the layering of images on top of language, of concepts. Modern images were for him images of the "third order": not images of the concrete world, but images of modern concepts themselves abstracted from images of the concrete world (Flusser, 2000/1983, p. 13). Images are furthermore for Flusser today "technical," that is: images of technical concepts, as modern language itself is the result of a rational-technical relation to the world. Flusser's hypothesis on the becoming technical of modern images is founded on the conception that since the widespread success of photography, our imaginary capacity has moved from internalized areas of imagination to the externalized mechanisms of the camera and other visual machines. These externalized mechanisms are then 
additionally — despite being external to us - even more obscure to us, hiding their imaginary capacity inside their black boxes of technology. Especially since the advent of the camera, it has therefore for Flusser been apparent that the way we conceive our world is becoming completely dependent on the ratio of image-technologies. We have no insight into the mechanisms of a camera's "black box"; for this reason we have to rely "blindly" on its technical way of translating the concrete world into images. This translation is done in the technical language of the camera and its ratio of optics and chemical processes (Flusser, 2000/1983, p. 14).

I think this layering of images on top of language, of concepts, as described by Flusser, is a better starting point than flatness to understand the epistemological change in the representational function of modern images. The question now arises: how can we then understand this "technicality" of images? To me, the differences between Boehm's and Foucault's approaches to images are in themselves revealing this new technical status of the image. Boehm, to put it shortly, would be interested in exploding or rather exploring the flatness of images from within phenomenologically. He locates the iconic difference in the indeterminate depth of the visual, therefore as a difference in contrast to the predicative function of language (Boehm, 2009/2006, pp. $219 \mathrm{ff}$ ). Foucault instead implodes this same flatness into a new material and concrete visibility in an understanding very close to the technicality of modern images as described by Flusser (Foucault, $2009 / 1971$, p. 30). Boehm in other words insists on trying to maintain a field of phenomenological translation into our imaginary with images, whereas Foucault relocates our relation with images into a mere external physical almost technical interaction.

Flusser's conception of modern images as being inscriptive, related to language in a kind of layering, is in line with Walter Benjamin's critical thinking about the image. This layering as understood by both thinkers is not straightforward though: for them, modern images are not illustrations of a subject matter as Greenberg feared. Here it can be useful to remember Benjamin's texts on similarity and the mimetic faculty (Benjamin, 1979a/1933; Benjamin, 1979b/1933). The most mind-boggling passages of these are the reflections on the different speeds with which we can access similarity. For Benjamin, similarity is a question of how to enter areas where "objects meet and enter into relationship with each other" (Benjamin, 1979a/1933, p. 68). Either one can enter this space of similarity post factum in a sensuous way. This is a slow way, where existing similarities are found and then brought into language semiotically, much in the way Greenberg opposed. Now for Benjamin there is the possibility of another kind of similarity, a "non-sensuous" similarity (Benjamin, 1979a/1933, p. 66). Access to these non-sensuous similarities is dependent on a certain high rapidity whereby the closed semiotic of language is surpassed for a moment for the body and mind to be able to enter active areas of producing similarities as connections to the world outside language -including "constellations" outside normal phenomenologically situated vision. In these small but dense essays, Benjamin is focusing on the "Schriftbild" (typeface) and the rapid mimetic "dance" of the writing hand and the reading eye creating mimetic similarity, but I believe his analysis also applies to images. The photographer Alexander Rodchenko, contemporary with Benjamin, created a series of captivating images along the same lines that experiment with such areas of non-sensuous similarity. Nearly any photo from especially Rodchenko's first years as a photographer from 1924 and onward will demonstrate an ability to rotate, merge, or shift different areas of the photos into each other producing similarities as an effect of a non-sensuous high rapidity of the image. Take the photo of his mother reading a newspaper on a table (Reading Woman, 1924), where the round shapes rotate or share position, most strikingly in the shifting between head and teapot: two round shapes with "noses." The image rotates these figures perpetualIy into each other's place regardless of their deictic linguistic function. We are in other words witnessing an opening of the arbitrary function of language; this opening creating an area of concrete external relocations taking place in front of our eyes. In Radio Listener (1929) there is more of a merging of round shapes again, developing around, with, and in the head. But maybe the most radical example of the scope and strength of this effect is the series of Pioneers photographed from above, when seen in connection with his Glass and Light series-both series shot around the same time (1928). Even when having only one photograph of the series in front of one's eyes, the pioneers still shift into objects and back again, and the glass bowls and glasses take on human proportions. Figures as objects, objects as figures. This is of course a vital formalism, but I believe these rotations, mergings and shifts also demonstrate an ability to relocate or reverse the agency of the knowledge-making inherent in perceiving. The dominant deictic function of language is surpassed repetitiously in photographs like these. 


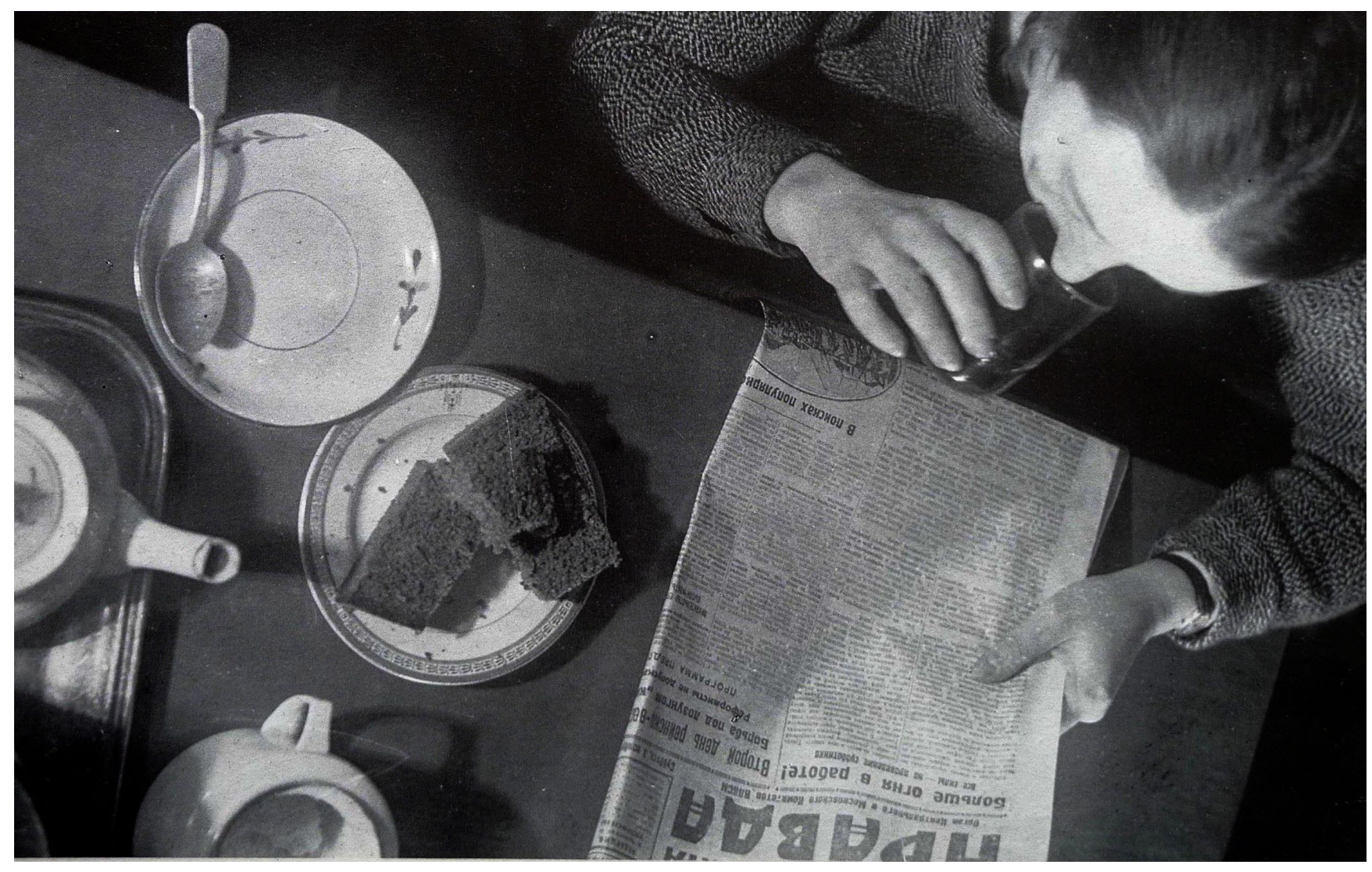

Alexander Rodchenko: Reading Woman, 1924.

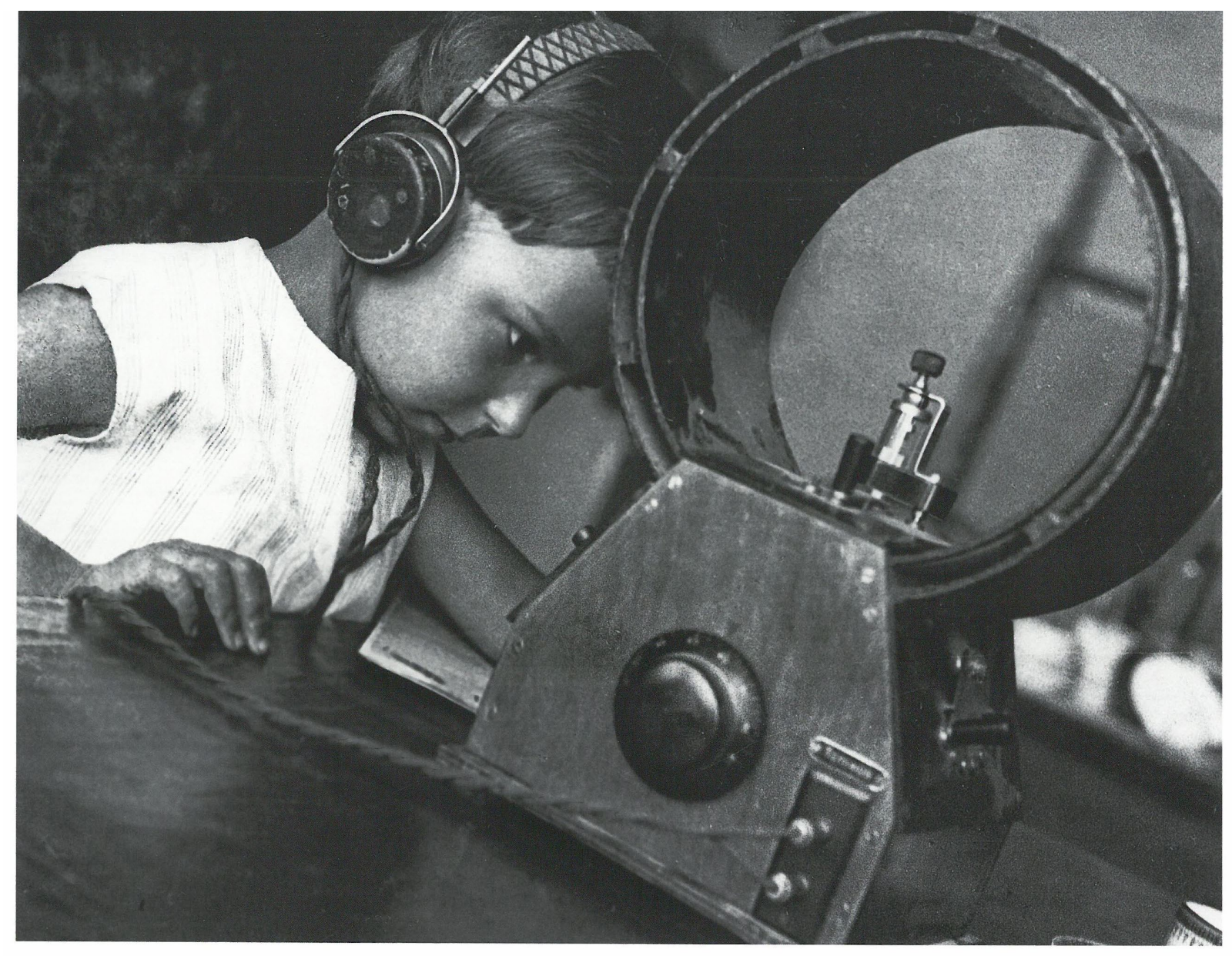

Alexander Rodchenko: Radio Listener, 1929. 


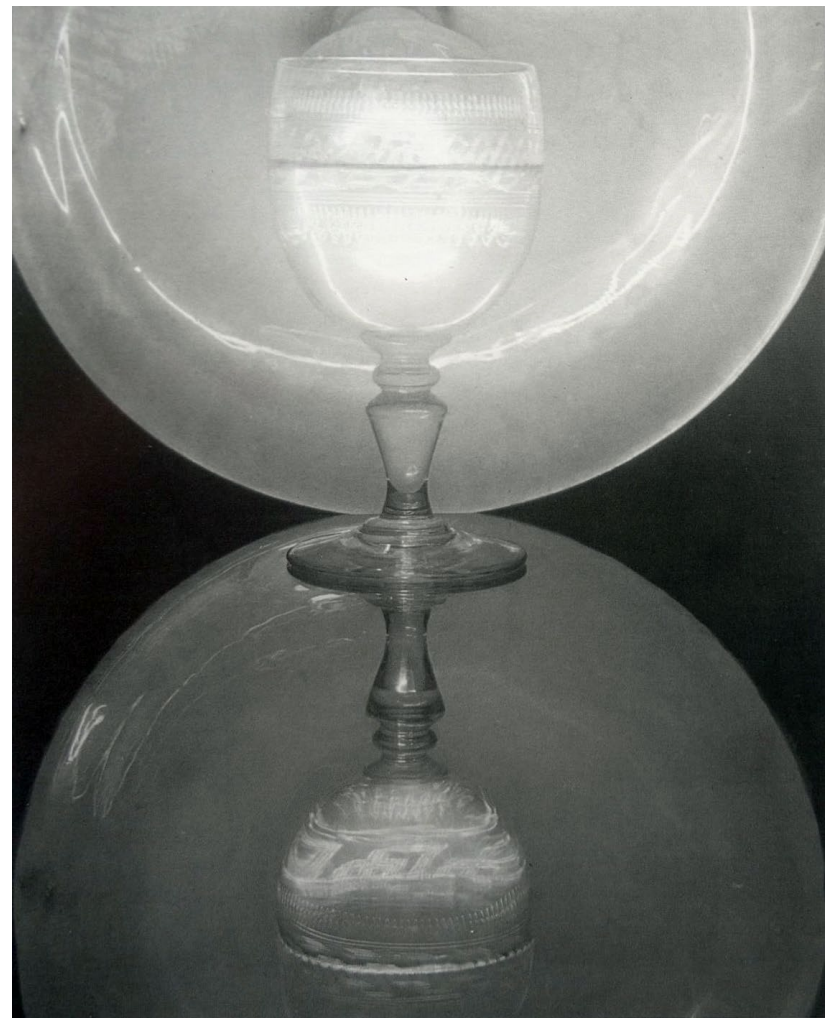

Alexander Rodchenko: Glass and Light, 1928

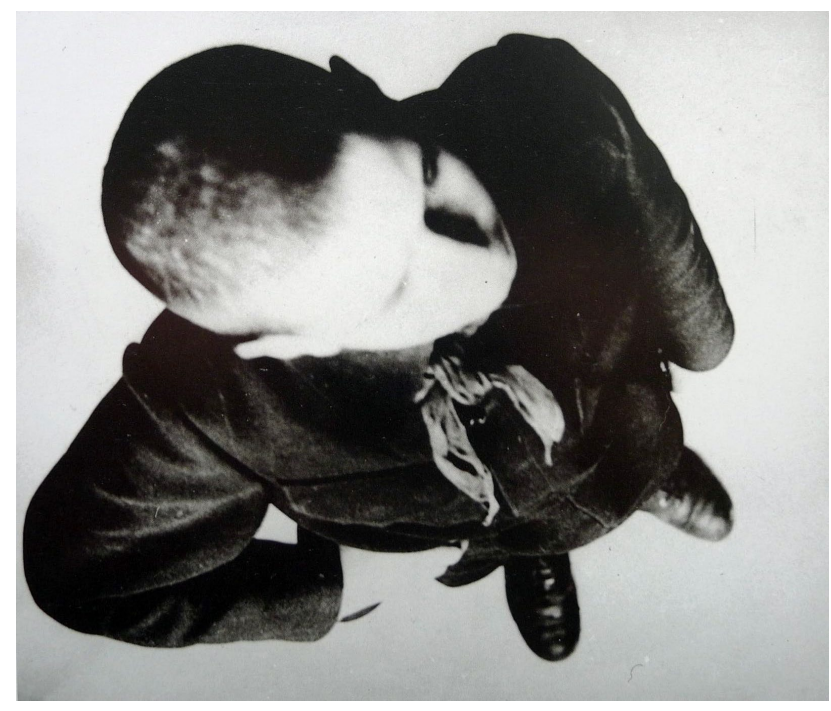

Alexander Rodchenko: Pioneer, 1929

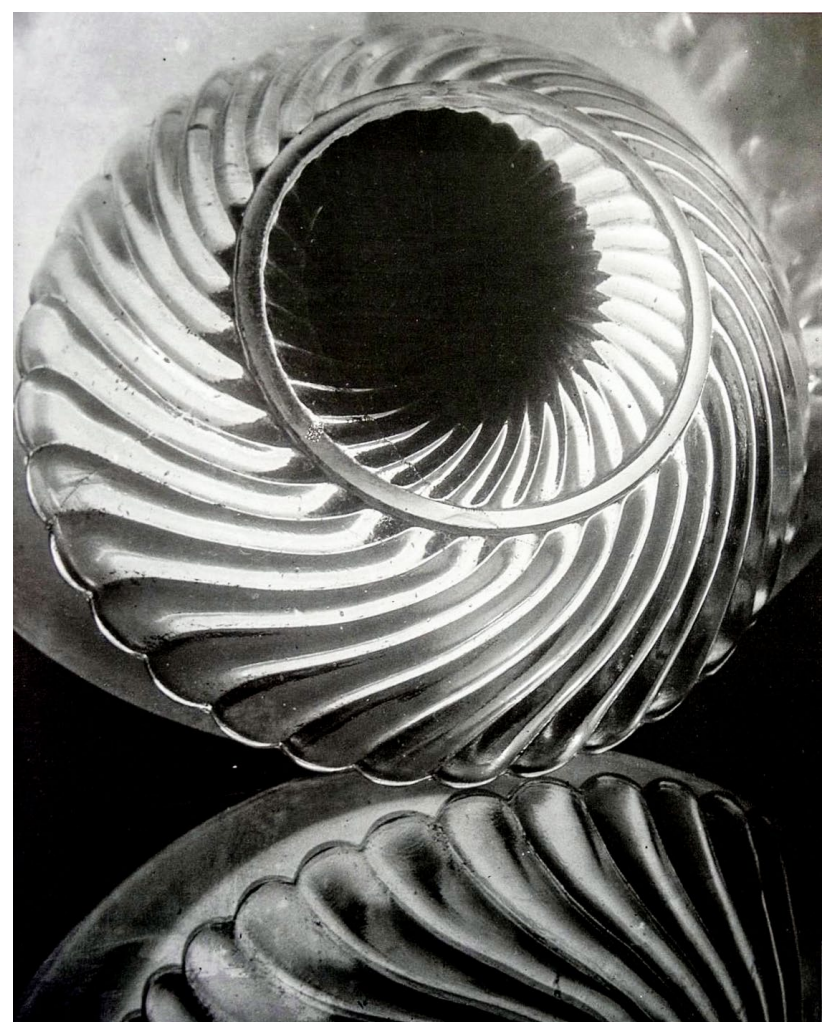

Alexander Rodchenko: Glass and Light, 1928

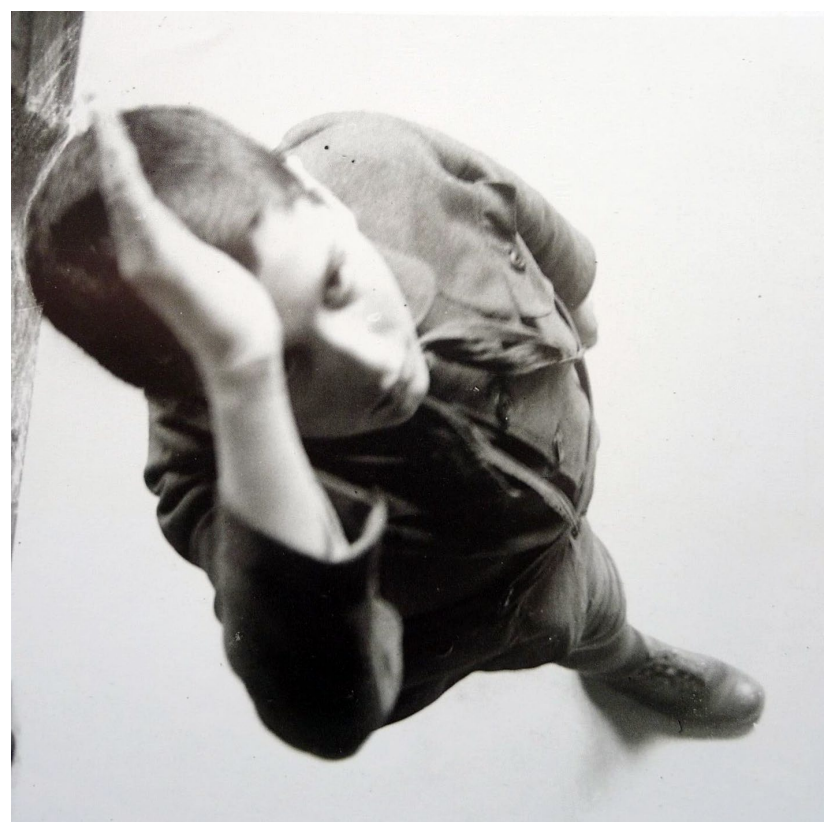

Alexander Rodchenko: Pioneer, 1929 


\section{BOEHM AND THE ANALYSIS OF “ICONIC DIFFERENCE"}

But no matter how captivating Benjamin's essays are, we have to be more specific when trying to analyze the layered relation of images with language. Gottfried Boehm's image theory and its central concept of iconic difference is precisely dealing with this relation. For Boehm, images are always fundamentally opaque in the sense that they are developing spaces inaccessible to both intentional perception and to the predicative function of language. "Images are not 'true' or 'false,' but they can be clear or dark," as he formulates it (Boehm, 2009/2006, p. 228).

Boehm is developing Husserl's concept of our appresentation or co-visualization of the shades of phenomenons. Images do not, according to Boehm, present themselves as three-dimensional objects to be intentionally explored and "thematically" grasped as Husserl described the perception of phenomenons in space. Images instead formulates two-dimensional spaces ranging from those transparently open to imaginary intentional operations to those more forcefully resisting imaginary intentionality. It is in this space between the transparent and the opaque, in this iconic difference as Boehm labels it, that the imaginary of images is developed. In other words, images are not disposed to immediate bodily or epistemological control, and their inaccessibility to direct thematic perception is also not to be understood as an impreciseness that perception and language must correct to restore the represented and its meaning. Images instead invert the logic of perception as described by Husserl (Boehm, 2009/2006, p. 227).

But how is this inversion more specifically enacted in the image? Boehm gives this example:

We will never reach the backs of represented people or objects or enter a Dutch interieur through the door in the background and observe things from there. The indeterminacy that Husserl identifies in the shading of the object now wanders from its back into the background of the representation. Images are opaque, and the transparencies that they open emerge because the background of the representation appears material, ambiguous and impenetrable. (Boehm, 2009/2006, p. 227)

Here we have the connection between opacity and transparency opening the imaginary of the image and at the same time the reversal between matter and imagination. The image is for Boehm a concrete event and what it shows is founded in what we cannot see. Images are opaque or, in other words, their imaginary spaces are developed by the energy of the indeterminate potentiality of the shade of normal perception. But they still address normal thematic perception according to Boehm, they are "deictic," in the end they point out new visions and new worlds for us that we can then perceive thematically.

The crucial point for Boehm, I believe, is to consider this inversion of perception as not just a reversion of the syntax of perception to be restored back into normal thematic perception, but to let this inversion be the defining condition for the space and the knowledge produced in the image. It is our everyday thematic perception that can and must be widened by the potentiality of the imaginary space of the image. For Boehm, as for Gadamer, to whom Boehm refers, images are capable of conducting a Seinsvorgang (an event of being): "Wiedererkannt wird überhaupt nichts, was man schon weiss oder irgendwo gesehen hat" (nothing is recognized that one already knows or has seen somewhere; Boehm, 2007 , p. 266). It is not a question of perceiving the image as a weak reproduction, an Abbild, but to enter the darkness of the imaginary. Then, and only then, will the image become an image, that is: something different from our normal, thematically controlled perception. An image can teach us to perceive even the most well-known spot, situation, feeling or energy differently.

\section{THE REPLACEMENT OF THE IMAGINARY WITH CONCRETE VISIBILITY}

Boehm's image theory is still founded on a final deictic rapport with a phenomenologically experienced space. His image-theory is therefore in my view to a certain degree-to come back to Vilém Flusser-proto-technical. In this respect it is well suited to show the difficulties one is facing when trying to describe the paradoxically concrete spaces of modern imagery. Boehm's phenomenology of the image is not intended to describe these concrete spaces in what we will call their double implosion from 1: the "Greenbergian" implosion of illusionist representation into material flatness to 2 : the concrete re-emergence of this flat materiality in re-presentation.

This double implosion can be illustrated by comparing two modern paintings that are exemplary to demonstrate this double implosion. An implosion that can be difficult to follow in a single painting alone. A painting by J. F. Willumsen from 1909 and one by Erik Hoppe from around 1925. 

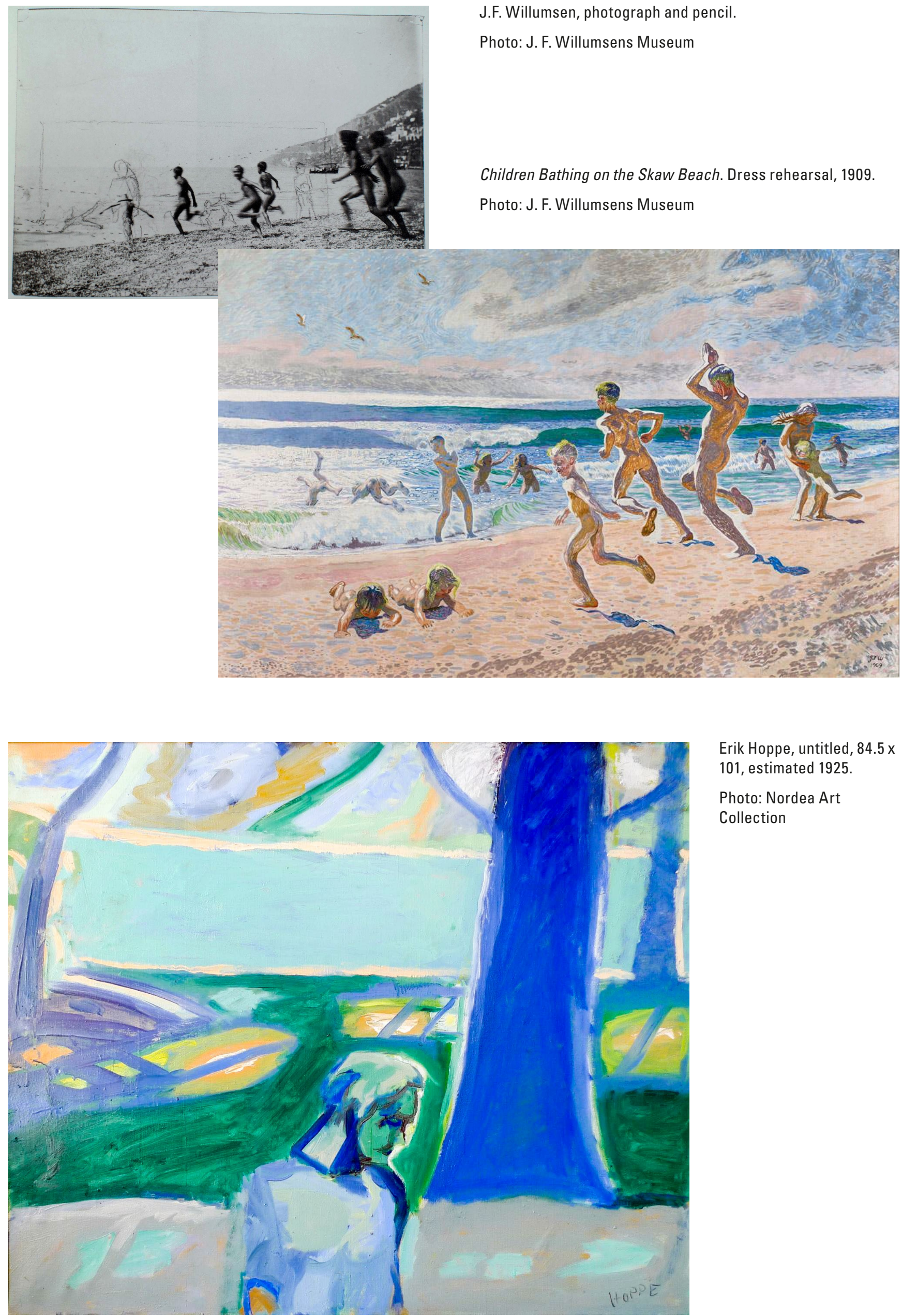

Erik Hoppe, untitled, $84.5 \mathrm{x}$ 101, estimated 1925.

Photo: Nordea Art

Collection 
I believe these paintings are well suited to show the scope and limits of Boehm's image theory. Especially Hoppe's painting apparently opens its imaginary transparencies because of its opaque backgrounds to thematic figures: The blue foregrounds, the blue shadows etc... opening imaginary areas: dreamy, melancholic for some. These are elements already present in Willumsen's painting. These paintings are in Boehm's terms not illustrations of language and subject matter, but are informing thematic perception and language through matter. But there is one important difference between the two paintings: Where Willumsen's painting shows blue shadows cast away from the figures, these blue shadows have imploded into form shadows in Hoppe's painting. One could say that in Hoppe's painting everything is background, on which grounds imaginary relations, iconic differences, between background and thematic fields are difficult or not important to establish. This is the implosion of the imaginary figural space famously formulated by Greenberg with his concept of flatness. You cannot "step into" the imaginary space of Hoppe's painting as you to a certain degree still can with Willumsen. But let us have a look at the paintings again: are they not both dealing with an imaginary of a very specific sort? Both paintings are what we would call overexposed had they been photographs. I believe this calls for a very different analysis than the one Boehm suggests. It calls furthermore at the least for a doubling of Greenberg's analysis.

This "overexposure" extends the canvas into the concrete space of the beholder. It is a physical impression of a contrasty light that denies to be developed through the iconic difference of the imaginary as Boehm's analysis demands. It is an implosion into the concrete space of the beholder, an explosion it is impossible to follow thematically and experience in the imaginary. What happens in a painting like Hoppe's, which is very observable standing in front of the real painting, is that the imaginary transparency implodes in overexposure and returns as the physical entity of very strong light coming from somewhere behind the canvas. The imaginary has been replaced by concrete visibility. When this happens in modern images they are often at the same time concealing themselves behind their apparently real appearance and presentness. But they are still images, just of a different kind, which we still do not understand properly. This is what Vilém Flusser described as the becoming "technical" of modern images. Flusser's thesis is that all modern images appear to us exactly as weak images. Images of the world, Abbilder, as in a photograph's — or these paintings' - direct technical registering of light. Or think of the race today towards higher and higher definition screens. But being this, according to Flusser, they are first of all no longer in a deictic rapport with a phenomenologically experienced thematic space as we are often led to believe. They are instead images of concepts, therefore technical. In Flusser's words: "[technical images are] not designed to alter the world out there but our concepts in relation to the world" (Flusser, 2000/1983, p. 17). Flusser's hypothesis on the becoming technical of modern images is, as already mentioned, founded on the conception that since the widespread success of photography, our imaginary capacity has moved from the internalized areas of imagination to the externalized mechanisms of the camera and other visual machines. These externalized mechanisms are then additionally — despite being external to us - even more obscure to us, hiding their imaginary capacity inside their black boxes of technology. Technology that stems from technical conceptual developments not directly visible to a phenomenologically situated vision.

Following this thought it is revealing that the photographs by Rodchenko-if we for a moment revert to them-were not dealing with overexposure but with composition: The two media have exchanged concepts on purpose. Boldly speaking, the formally avant-garde photography of these years (Straight Photography, Neue Sachlichkeit, Constructivism, etc.) was gradually borrowing what was developed in the old art of painting, namely composition, and then handling this effect to the extreme, handling it as a concept, distorting it-whereas paintings like Hoppe's are borrowing what we are accustomed to ascribe to photography, namely the concept of the registering of light, and then handling this in a comparable extreme manner, to show us this concept itself. In line with this, it is striking that even Willumsen sketched his future painting on a photographic study of children bathing.

For Flusser, modern images are by definition inescapably weak from a phenomenological standpoint: They are technical, they are dealing with concepts in a way that is still difficult for us to perceive. Flusser is interested in registering how images disappear in their technical nature and how they can deal with this technicality to remain images of it.

\section{THE SPACE OF DISCURSIVE VISIBILITY}

How are we now more precisely to describe Hoppe's painting in relation to this? Why are the cast shadows abandoned and turned into form shadows in this image? And what is revealed between the back-lit overexposure and the form shadows? If it is neither a thematic space, nor an imaginary space, 
it could be a technical space or maybe it would be more precise to designate this space a space of discursive visibility. With this I am referring to and elaborating on Michel Foucault, who tried to describe the possibility of such a space in a slide-lecture holding the title Manet and the Object of Painting (Foucault, 2009/1971). Foucault holds Manet to be the key to all modern painting after Manet, and in the lecture registers how in Manet's paintings a concrete crossing of the represented space of the canvas into the space of the beholder fixates the beholder in an irreal concrete space. The represented space has paradoxically imploded to become concrete, which is what gives the title to the lecture: The painting has become a "painting-object," it has become a concrete visibility: "Manet reinvents (or perhaps he invents) the picture-object, the picture as something colored which clarifies an external light and in front of which, or about which, the viewer resolves. ... this reinsertion of the materiality of the canvas in that which is represented" (Foucault, $2009 / 1971$, p. 31). It is crucial to notice here that Foucault does not do away with representation, but believes the painting of Manet to be able to "clarify" an external light and "resolve" the viewer. One now can and should also ask which space this "reinsertion of the materiality of the canvas in that which is represented" leaves to the viewer? Foucault's implicit answer is that it leaves him no real space except for the relocations of the concrete painting-object "resolving" him: Resolving him in the concreteness of the discursive space Foucault spent large parts of his academic life to understand.

Two of Foucault's examples are especially useful for us here: Le Chemin de Fer and Olympia.

In Le Chemin de Fer, the attention of the two figures portrayed is clearly pointing out this new concrete space of the canvas-The spaces behind

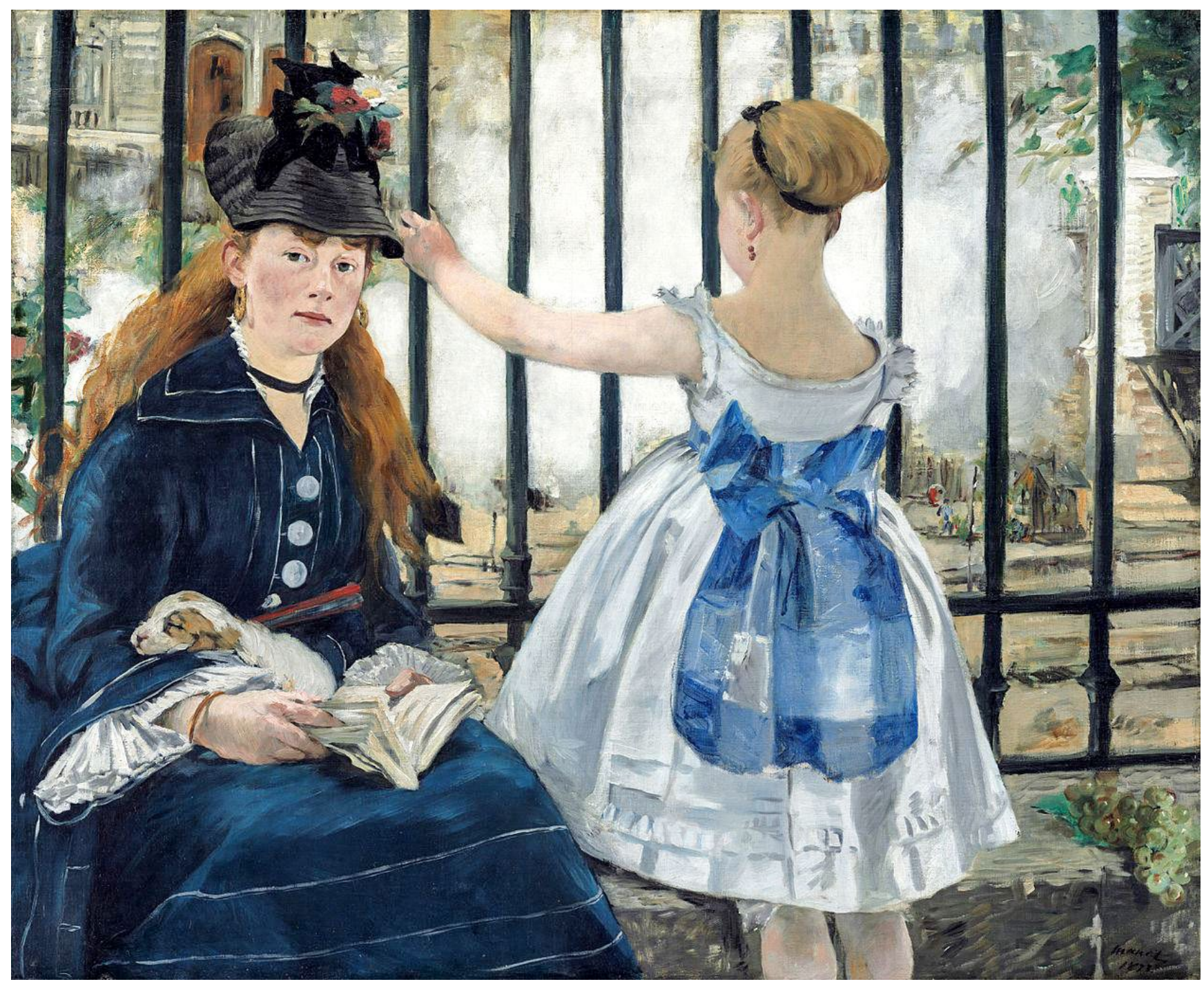

Édouard Manet: Le Chemin de Fer, 1872-73, 93,3 x 111,5.

Photo: National Gallery of Art, Washington 
and in front of the material canvas. The back of the little girl and her attention to something behind and outside of the frame of the canvas makes us, according to Foucault, want to remove the canvas and its steam or walk behind it to see what she sees (Foucault, 2009/1971, p. 54). The canvas is a concrete object here and what it shows is no longer founded in what we cannot see (e.g. Boehm's concept of "indeterminacy"), but what we can see-or more precisely what we ought to be able to see, were the canvas not in the way of our gaze. The painting has become a concrete object and this even more clearly in the famous Olympia.

We notice in Olympia as in Hoppe's painting: no cast shadows, only hints of form shadowing. The reason is simple according to Foucault: There is no internal or external represented light source, no alluded space and therefore no cast shadows, and secondly and more important: With no cast shadows no privileged viewpoint. The painting has become an object. But not a normal object subject to thematic perception, because it insists on indicating an even amount of light illuminating the surface head on in a 90 degrees angle. This is crucial: the light illuminating this canvas from the space of the beholder is blocked and then "evenly" distributed perpendicularly along the whole surface leaving no privileged space for the beholder. The light split by the concreteness of this canvas is not turned into a represented light, neither is it a real physical light but in a way both-or the impossible combination of them, what we can call a "discursive light." Foucault formulates this more elegantly and indirectly: "A light which comes from in front, a light which comes from the space found in front of the canvas, which is to say that the light, the luminous source indicated, which is assumed by the very lighting of the woman, this luminous source, where is it, if not here, precisely where we are?" (Foucault, 2009/1971, p. $66)$. Notice that Foucault does not imply an imaginary light coming from "inside" the viewer but are using exterior spatial terms, but then again also not referring to a real exterior light source: The light is "precisely where we are"-which is at the same time a phenomenological paradox and the possibility of performing the kind of relocations I would, following Foucault, call archaeological. The phenomenological paradox (how can the light be "precisely where we are"?) explains the unrest one can experience in front of a painting like Olympia or Hoppe's painting: Where to position myself to not be

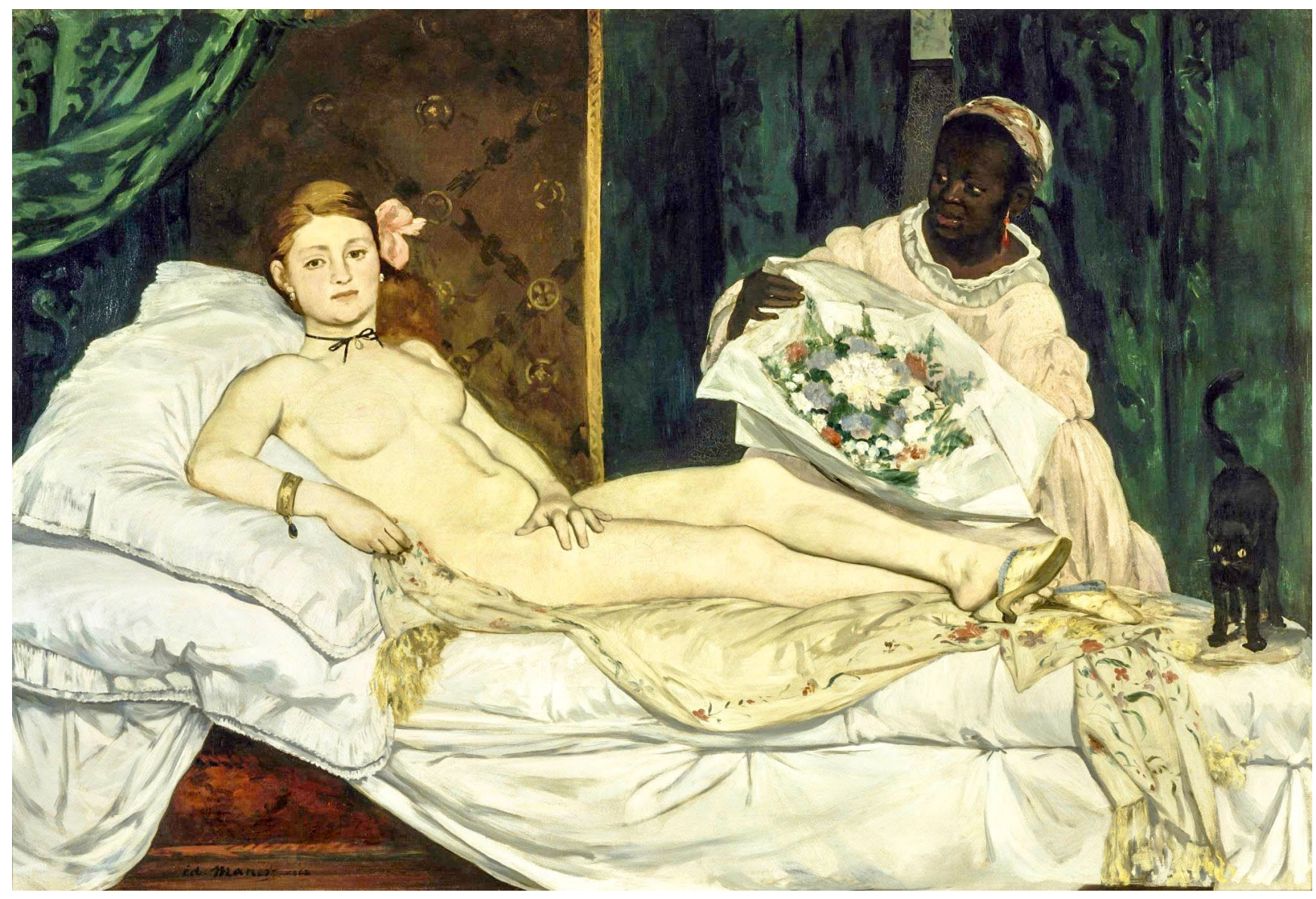

Édouard Manet: Olympia, 1863, 130 x 190.

Photo: Musée d'Orsay 
in the way of the "luminous" source of the representation-to be able to see it, to reveal it? We are standing in an irreal concrete space. In front of modern paintings like these we are suddenly standing in the form-shadow of our own discourse. To place its viewers in the concrete form-shadow of their own discourse is the key operation high modern images like these are able to perform. This operation requires a crossing of the imaginary space of the image and the concrete physical space of the canvas and its surroundings. In front of images like the ones described in this article, the viewer's physical body is therefore clearly situated in an imaginary space of the very concrete sort Foucault described as a discursive space. This is not a space for us as viewers to light up or differentiate with our appresentative imagination, it is a space already lit up before we enter the space in front of the canvases and photographs. In this space we want to relocate to be able to discover this light-source that we eradicate with our physical presence-but the privilege and illusion of movement is no longer ours. It is discourse that moves or relocates us in its fixating ways. This is what Lyotard in his own way summed up as the “stage" of signification (Lyotard, 2011, p. 9).

It is the exact fixation these images perform on us as beholders that is the key to understanding the discursive visibility images like these are trying to show. In the concrete space of this fixation we ourselves cast no shadows but are subjected to an overexposed conceptual light source pointing to our own discursive body as only an indistinct form revealed by the form shadows of discourse and their imprecise fading out of light. In Foucault's words: “We enter a pictorial space where distance does not offer itself to be seen, where depth is no longer an object of perception" (Foucault, 2009/1971, p. 41).

\section{TO RENDER VISIBLE OUR BEING POSITIONED BY CONCEPTS}

If modern images are technical, images of concepts, as claimed by Flusser, Hoppe's painting is a critique of our concept of light as something given directly to perception. But at the same time it is a critique of the other side of this conception, namely the concept of the imaginary as an opaque light source illuminating our world as Boehm would have it. I believe that a painting like Hoppe's is trying to show us the concrete impossible crossing-point of visual perception and the imaginary in what I in this article have labeled a discursive light: The highly contrasty white and blue overexposed areas of stream and tree repeated in the form shadow of the throat and the shoulder of the figure in the "foreground" as if wanting to push the figure out of place, relocate it, to show us the impossibility of representing it clearly - as with the chromatic distortion appearing along sharp edges in photographs.

To sum up: We have to learn to understand the critical potential of modern images with a vocabulary that can describe their discursive visibility as concrete relocations: Confronted with the concrete blinding light from Hoppe's painting we try unrestfully to relocate to enter this discursive crossing-point between external and internal light, between external (exogenous) and internal (endogenous) images. It is this exact crossing-point that Flusser in line with Foucault believes to be the only possible area of modern images if they are to become images at all. An area in which, from inside it, relocations between head and teapot, head and receiver, pioneers and glass bowls can take form.

The technical imagery as it is described by Flusser and Foucault is no longer inviting us to enter the darkness of an imaginary scene to let our imagination open its transparencies. To the contrary, here we are met by overly distinct light and high-speed compositions from concepts impossible to fixate in an image, leading us in the best case to discover the opaqueness and density of our own being positioned by these same concepts. Our bodies are discursive bodies. If we have to keep seeing and sensing the critical project of modern art, we thus have to shift emphasis from an alleged (e.g. Greenbergian) self-reflexivity in its medium to the actual potential of its producing of concrete relocating visibilities in our world of technical images; so persuasive because of their being so difficult to see. We have to perform this shift in emphasis to try to confront and make visible the knowledge integral to our acts of perceiving. In other words, we must try to enter the space of discursive visibility that modern art already long ago entered in diverse ways, some of which we have pointed to here.

\section{REFERENCES:}

Benjamin, Walter. (1979a). Doctrine of the similar (1933). New German Critique, 17, Special Walter Benjamin Issue (Spring, 1979), pp. 65-69. [German original: Lehre vom Ähnlichen. (1977). In Tiedemann, Rolf, \& Schweppenhäuser, Hermann (Eds.), Gesammelte Shriften II, pp. 204-210. Frankfurt am Main: Suhrkamp]. (Original work published 1933)

Benjamin, Walter. (1979b). On the mimetic faculty. In One-Way street and other writings. NLB, London. [German original: Über das Mimetische Vermögen. (1977). In Tiedemann, Rolf, \& Schweppenhäuser, Hermann (Eds.), Gesammelte Shriften II, pp. 210-213. Frankfurt am Main: Suhrkamp]. (Original work published 1933)

Boehm, Gottfried. (2007). Wie Bilder Sinn erzeugen. Berlin: Berlin University Press. 
Boehm, Gottfried. (2009). Indeterminacy: on the logic of the image. In Huppauff, Bernd \& Wulf, Christoph (Eds.), Dynamics and performativity of imagination. The image between the visible and the invisible. New York: Routledge. (Original work published 2006)

Foucault, Michel. (2009). Manet and the object of painting. London: Tate. (Original work published 1971)

Flusser, Vilém. (2000). Towards a philosophy of photography. London: Reaktion. (Original work published 1983)

Flusser, Vilém. (2011). Into the universe of technical images. Minneapolis: University of Minnesota Press. (Original work published 1985)

Greenberg, Clement. (1986). Towards a newer Laocoön. In The collected essays and criticism, Vol. 1, 1939-1944. Chicago: University of Chicago Press. (Original work published 1940)

Lyotard, Jean-Francois. (2011). Discourse, figure. Minneapolis: University of Minnesota Press. (Original work published 1971)

\section{CORRESPONDENCE}

\section{Michael Kjær,}

University of Copenhagen,

Department of Arts and Cultural Studies,

Karen Blixensvej 1,

2300 København S

Denmark

E-mail: michaelk@hum.ku.dk

Published online, 2017

ISSN 1749-3463 print/ISSN 1749-3471

https://doi.org/10.14434/artifact.v4i1.13129

(C) 2017 Artifact 